\title{
Reporting the polls: the quality of media reporting of vote intention polls in the Netherlands
}

\section{Tom Louwerse $^{1}$ D $\cdot$ Rozemarijn E. van Dijk ${ }^{2}$}

Accepted: 10 June 2021

(C) Springer Nature Limited 2021

\begin{abstract}
This article examines the media coverage of vote intention polls in the Netherlands. We assess whether the quality of media reporting on polls depends on the availability of information regarding the quality in pollster's reports. Our analysis of the quality looks at three different quality measures: (1) mentioning WAPOR items, such as field dates, sampling method, and polling method, (2) mentioning the margin of error, and (3) the correct interpretation of (in)significant changes and differences. The Netherlands provides an interesting case, because there is variation over time and across pollsters in the way they report their polls as well as the increased popularity of a polling aggregator. Our findings indicate that the overall quality of Dutch coverage of polls is low. When a pollster mentions the margin of error in its report, media reports on that poll are more likely to include this information and to correctly interpret the significance of differences between two parties. This effect is particularly visible when the pollster provides uncertainty intervals in its headline figures.
\end{abstract}

Keywords Opinion polls $\cdot$ Media $\cdot$ Survey $\cdot$ Public opinion

\section{Introduction}

'Polls have become an addiction' (Trouw 2012); 'Crazy because of the polls' (NRC Handelsblad 2012); 'On a leash by the polls' (Mudde 2012). These are just a few newspaper headlines during the 2012 parliamentary election in the Netherlands. They suggest that journalists believe that opinion polls, particularly vote intention

Tom Louwerse

t.p.louwerse@fsw.leidenuniv.nl

Rozemarijn E. van Dijk

rozemarijn.vandijk@uantwerpen.be

1 Institute of Political Science, Leiden University, Wassenaarseweg 52, 2333 AK Leiden, The Netherlands

2 Department of Political Science, University of Antwerp, Antwerp, Belgium 
polls, have a lot of influence on the reporting of election campaigns. Media reports on opinion polls report which party is the largest, whether parties win or lose, and whether differences between parties grow or decline. Besides framing parties as 'winners' and 'losers,' polls can also have a direct effect on the campaign: sometimes media use them to determine who is invited to television debates. In 2017, RTL Nieuws planned to invite the four largest parties in a poll of polls (Peilingwijzer, 'polling indicator'). However, when the difference between the fourth and fifth party turned out to be not statistically significant, RTL decided to invite five parties to the debate, which in turn led to the withdrawal of the two largest parties.

How media cover opinion polls have been criticized by both academics and polling companies. Existing studies show that opinion poll reporting does in many cases not comply with minimal disclosure standards and focuses on non-significant changes (e.g., Bhatti and Pedersen 2016; Oleskog Tryggvason and Strömbäck 2017; Pétry and Bastien 2013; Szwed 2011). Our study adds to this existing body of knowledge by examining the link between the quality of pollsters' survey reports and the quality of the news reports on polls. Our general expectation is that when pollsters offer more information about their polling methods and the margin of error associated with their poll, media reports are more likely to report this type of information as well.

We study the changes in the coverage of vote intention polls in the Netherlands between 2010 and 2017. There is substantial variation in the way pollsters present their opinion polls: some offer hardly any information in their press releases on how the poll was conducted and the associated margin of error, while other pollsters include a lot of information. In addition, the use of a polling aggregation model (Peilingwijzer), which emphasizes the importance of looking at trends and taking into account the margin of error, has increased from being non-existent to a widely used instrument. Therefore, this presents a good case to analyze the impact of the quality of pollsters' reports on how party vote intention polls are presented in news media. Press coverage of polls in the Netherlands has previously been shown to be low, but this concerned polls in the 1986 parliamentary elections and this was a purely descriptive analysis (Leijenaar and Niemöller 1987; Van Holsteyn and Andeweg 1988). We analyze opinion poll reporting in (both broadsheet and tabloid) newspapers and on news websites during 5 weeks before the national elections, as well as the quality of the reports prepared by the pollsters. We use three different measures to assess the quality of media reports on polls. First, the World Association for Public Opinion Research (WAPOR) suggests a list of 16 items that should be included in a survey report, such as the sample size and field dates; we count the number of items included in pollsters' survey reports and news reports. Second, we check whether the margin of error is included in pollsters' survey reports and news reports. Our third measure, and perhaps the most important one, is whether changes between polls and reported differences within polls were correctly interpreted, taking into account statistical significance.

Our study shows that the quality of Dutch coverage of polls is quite low, which makes the Dutch case similar to other countries. Dutch media report very few, if any, of the items suggested by WAPOR, including the margin of error of a poll. We find a strong association between the pollster including uncertainty intervals in their 
headline figures and the quality of opinion poll reporting. If a party's standing in the poll is reported as '15-19 seats,' media are more or less forced to include the information about the uncertainty of the estimate in their articles. Therefore, we suggest that poll companies in their reports focus on the uncertainty intervals rather than the point estimates.

\section{Polling aggregation and the coverage of opinion polls}

Scholars and practitioners have shown an interest in the effects of opinion poll reporting in the media on voters, politicians, and public policy. When the effects of polls are discussed, a distinction is often made between the effect of polls on the participation in elections and voting preferences (Hardmeier 2012). Regarding voter turnout, the effect of opinion poll reporting seems marginal (Hardmeier and Roth 2001; Morton et al. 2015), although a majority of American and German journalists think that polls can influence the turnout or voting preferences (Wichmann and Brettschneider 2009, p. 516). Recent research also indicates that exposure to polls can increase voter turnout among young voters (Stolwijk and Schuck 2019).

Polls are also thought to have an effect on voting preferences. In general, three effects can be distinguished: the bandwagon effect; the underdog effect; and strategic voting (Moy and Rinke 2012, p. 229). The bandwagon effect entails that voters decide to vote for the politician or party that is leading in the polls, while the underdog effect means that voters choose the party or politician that is losing. The evidence that supports the bandwagon effect is small but substantial, at least in some studies: voters change their preference in the direction of a party that is leading into the polls. The size of these effects, however, depends on the way in which opinion polls are reported in the media (Hardmeier 2012). Nevertheless, politicians fear the polls for their potential influence on voters, and therefore, polls about vote intentions are in some countries, ${ }^{1}$ such as France and Italy, (partially) banned before or on election day (Petersen 2012, p. 50).

If polls potentially affect voting behavior, it can be argued to be of crucial importance that poll outcomes are reported correctly (Bhatti and Pedersen 2016; Andersen 2000; Brettschneider 1997). We distinguish two approaches to measure media coverage of opinion polls: a quantitative and a qualitative approach. The quantitative approach looks at which polls get covered in the media and the trends in opinion poll coverage. Previous research indicates that there has been an increase in poll coverage (e.g., Pétry and Bastien 2013; Szwed 2011; Sonck and Loosveldt 2008; Frankovic 2004; Brettschneider 1997). This is not strange, since research shows that readers are mostly interested in horse-race-framed news (e.g., Iyengar et al. 2004). If voters want polls, journalists will provide them (Matthews et al. 2012, p. 264). It is debated whether an increase in poll coverage should be considered as positive or negative, because it could frame politics as a strategic game or a 'horse race' rather

\footnotetext{
${ }^{1}$ For an overview of countries with substantial, minor or no legal restriction on the publication of preelection polls, see Petersen (2012), p. 57.
} 
than focusing on substantive policy issues (Aalberg et al. 2011, p. 163; Oleskog Tryggvason and Strömbäck 2017, p. 3). Framing politics as a strategic game means that there is an extensive focus on whether parties are winning or losing. Polls fit perfectly in this frame, because they supply the data about who is 'leading' and who is 'falling behind' (Patterson 2005, p. 718). It is argued that as a consequence of using the strategic game frame, citizens will receive less political information, be less engaged and that political cynicism will increase (Aalberg et al. 2011, p. 165; Patterson 2005, p. 722).

The attractiveness of using polls in the news is not only because of the readers' demand, but also because of the changes in journalism. Since there is a 24 -h demand for news, journalists need news every moment of the day and polls can provide such news (Rosenstiel 2005, p. 698). Polls can provide a 'continuous stream of fresh news' (Stolwijk 2017, p. 33). Wichmann and Brettschneider show that the majority of both German and American journalists use polls as information for their articles (2009, p. 512). Moreover, polls provide journalists with the opportunity to interpret elections themselves (Matthews et al. 2012, p, 265; Rosenstiel 2005, p. 700; Stolwijk 2017, p. 33). Polls also create a feeling of certainty and credibility for readers (Koetsenruijter 2011, p. 78); they provide news coverage with a scientific and objective connotation (Stolwijk 2017, p. 33). But also, most journalists perceive the quality of opinion polls as high (Wichmann and Brettschneider 2009).

Since polls are increasingly covered, it is important to understand how they are reported. The qualitative approach focuses on the quality of media reports on polls. In this case, scholars often test whether news reports include the items that are recommended by the World Association for Public Opinion Research (WAPOR), such as the sample size, the wording of the specific question, fieldwork dates, and the margin of error. The inclusion of these items allows citizens to critically assess the polls (Strömbäck 2009, p. 59; Holtz-Bacha 2012, p. 107). According to Welch, the inclusion of methodological information will lead to 'greater public understanding of polls and to an increase in the public's confidence in them' (Welch 2002, p. 112). Wichmann (2010) found that when only 1 AAPOR criterion was mentioned in a newspaper article, a reader was less able to encode and store this information than when a medium amount of 4 AAPOR criteria was reported. However, there can be an information 'overload,' when 8 criteria were mentioned, this hindered the reader's ability to encode and store the information (Wichmann 2010).

Studies that examine whether methodological information is included in newspaper articles clearly show room for improvement in the way news media cover polls (see Table 1 for an overview). On average, only three of the WAPOR items are included in at least $50 \%$ of news reports: survey institute $(79 \%)$, commissioner of the poll $(67 \%)$, and fieldwork dates (50\%). Sample size is reported, on average, in $43 \%$ of news stories, while the margin of error is explicitly mentioned in only a quarter of news reports. The sampling method is reported least often, only $17 \%$.

There is, however, variation between countries and studies. For example, Flemish newspapers only reported the survey institute in 16 percent of the articles (Sonck and Loosveldt 2008, p. 495). Overall, the Flemish newspapers reported far less methodological information than newspapers in other countries. Danish newspapers performed on almost all methodological criteria better than the other newspapers 


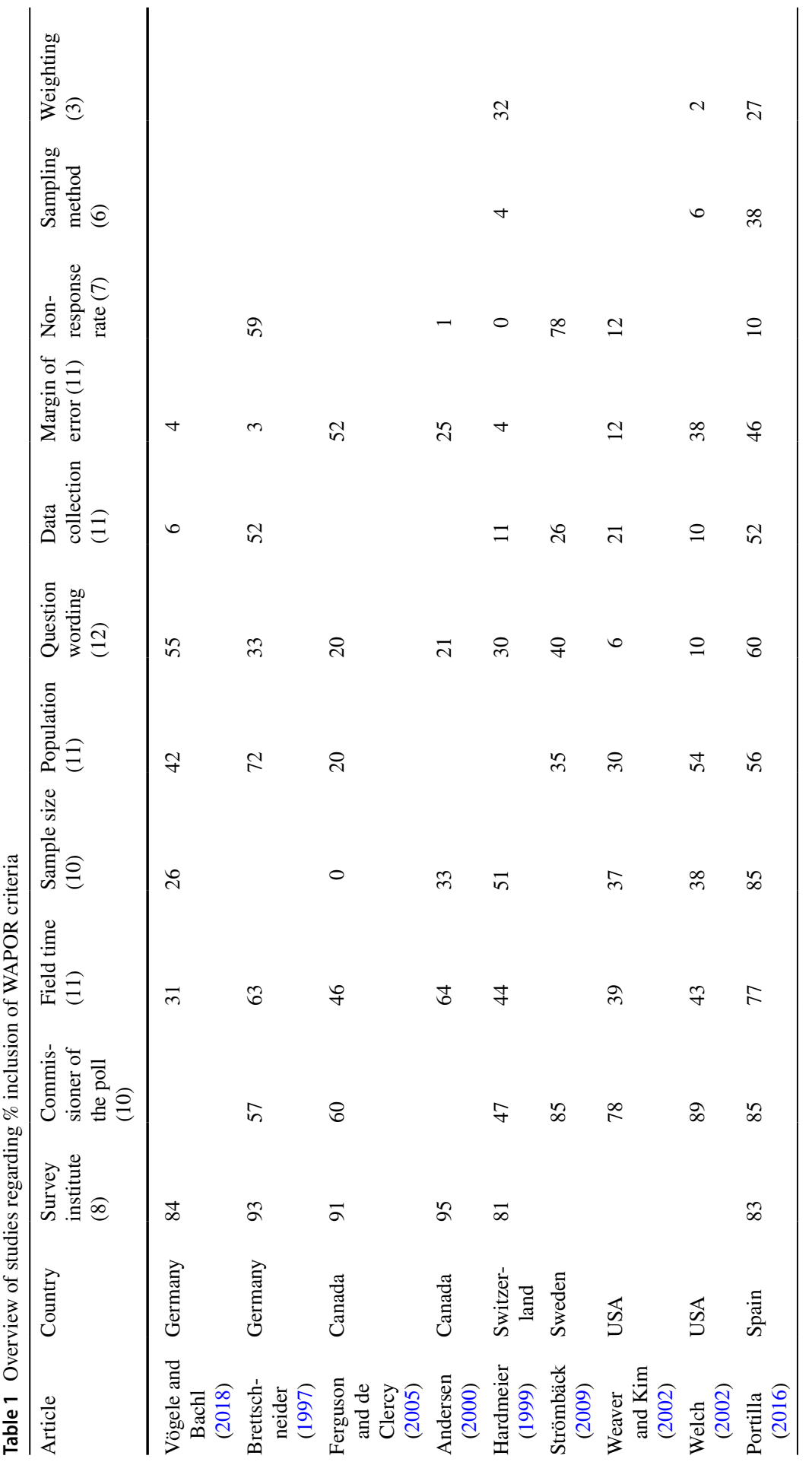




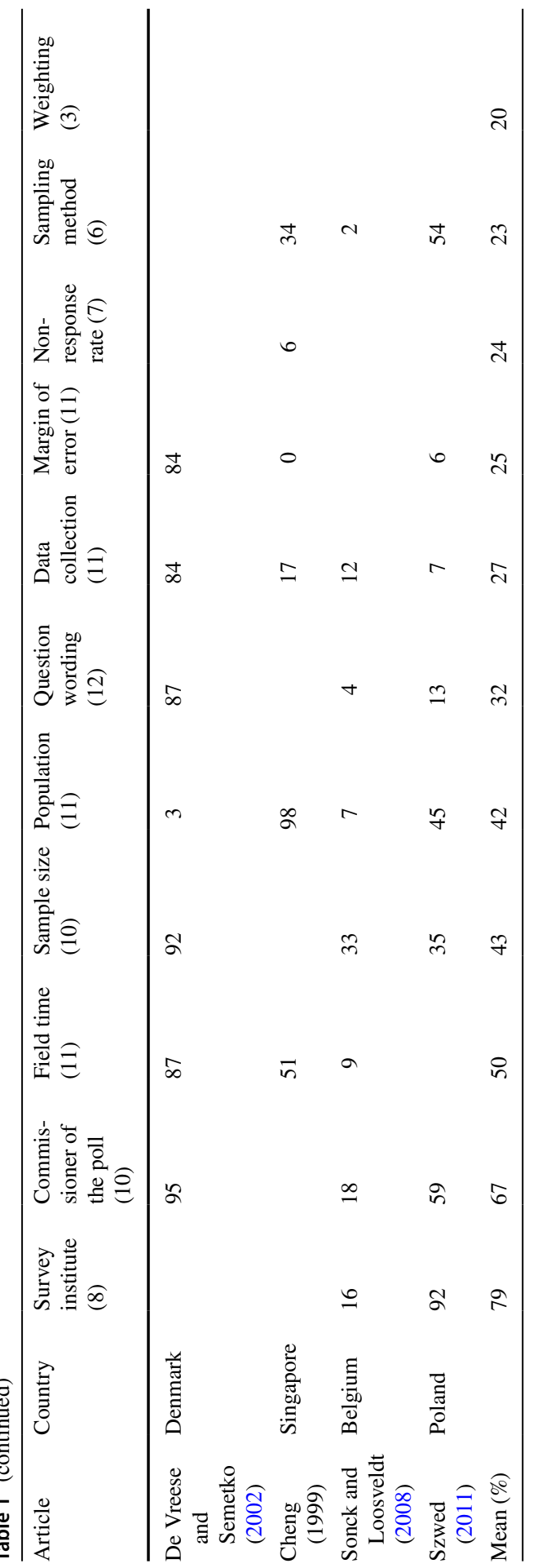

站。 
(except for mentioning the population). De Vreese and Semetko recognize that these scores are relatively high compared to other studies (2002, p. 383). A reason for this deviation could be that the methodological criteria were counted for only 37 articles that appeared on the front page in a broadsheet outlet. With regard to the inclusion of information about the population of the study, Chang found that almost all Singaporean newspapers articles did so 98\% (1999). The inclusion of information about the data collection was least often done by German newspapers: only in $6 \%$ of the articles (Vögele and Bachl 2018). The margin of error was not often reported, however. In Singapore, for example, it was never included in an article about polls. Danish newspapers on the other hand mentioned the margin of error in $84 \%$ of the articles. In Spain, where it is legally required to mention the margin of error, the margin of error was only mentioned in $46 \%$ of the articles (Portilla 2016, p. 41). Whether weighting is reported is studied least often, in only 3 studies (see Table 1).

One could argue that the inclusion of the extensive list of 16 items listed in the WAPOR Code of Professional Ethics and Practices (WAPOR 2018) is a good standard for a survey report, but this might not be suitable for newspaper articles. For example, for reasons of space, it is hardly possible to include a copy of the questionnaire (item 13) in a news report on a poll. Moreover, not all of the WAPOR items apply to aggregate polls, which have become increasingly prominent in media coverage. For example, for aggregate polls based on Bayesian smoothing, it makes less sense to report the number of respondents or fieldwork dates, because these methods make use of all available polls. Finally, one risks information overload that will hinder the reader's ability to understand and recall the poll results (Bhatti and Pedersen 2016, p. 131; Wichmann 2010). Thus, while we incorporate the number of WAPOR items in our analysis, we argue that it is only a partial indicator of the quality of opinion poll reporting.

Oleskog Tryggvason and Strömbäck (2017) argue that mere counting whether WAPOR items are included in newspaper articles does not truly measure the quality of covering polls. They argue that if we expect journalists to report correctly and in a reliable manner, we should check if they use the tool that ensures reliability of opinion polls: the margin of error (Oleskog Tryggvason and Strömbäck 2017, p. 4). We agree that a correct reporting of the margin of error is of particular importance for the interpretation of poll results, and therefore, we consider this a second aspect of measuring the quality of opinion poll reporting. Of course, the margin of error of a poll does not quantify all uncertainty associated with polling nor potential biases, but we argue that at the very least, the margin of error should be taken seriously when polls are reported.

Beyond reporting the margin of error, we would argue that the correct usage of this margin is of central importance in opinion poll reporting. Larson (2003) found that half of the reports on US network news that reported a margin of error, interpreted this margin inaccurately. Journalists claimed that one candidate was leading, while their lead was in fact within the margin of error (Larson 2003). Pétry and Bastien (2013) found similar results for Canada. Especially those reports that covered diachronic horse races - the rise or fall of a party between two successive polls-reported or used the margin of error incorrectly. Similarly, Bhatti and Pedersen concluded that Danish journalists interpreted 'statistical noise as meaningful 
variation' (2016, p. 136) and for Sweden (Oleskog Tryggvason and Strömbäck 2017, p. 15) and Germany (Vögele and Bachl 2018), similar conclusions were drawn regarding the interpretations of insignificant (diachronic) comparisons as if they were significant. Also in Denmark, newspapers are more likely to report polls about change. Even when the change in the polls is insignificant, journalists do create a story about change (Larsen and Fazekas 2019). Therefore, a third aspect of our analysis of the quality of opinion poll reporting is the accuracy of reports on the differences in party support, diachronically and synchronously (the difference between two parties in one poll).

\section{Better survey reports, better news reports?}

Our main expectation is that the quality of news reporting on polls is related to the quality of survey reports of pollsters. Pétry and Bastien (2013) found that journalists, when uncomfortable using statistical knowledge, rely on pollsters' reports since the pollsters are expected to report methodological information correctly. Especially when journalists covered diachronic horse races, the idea that a certain party rises or declines between two successive polls, the interpretation of the pollsters was important: when pollster's interpretations were inaccurate, journalists were always inaccurate in their interpretation (Pétry and Bastien 2013, p. 18). Portilla also encourages pollsters to improve their reports, since some mistakes in newspaper articles were due to incorrect pollster reports (Portilla 2016, p. 44). Polish newspapers reported more methodological information when they conducted the polls themselves, because of the mere availability of the data (Szwed 2011, p. 71). The availability of methodological information, thus, seems to matter.

We should, however, state that the effect for our first dependent variable, the number of WAPOR items included in the news poll, might be weaker than for our other indicators of quality. Including an increasing number of items takes up space in a newspaper article and, thus, decreases space for a substantive interpretation of polls. Moreover, the inclusion of too many technical details hinders the recall of poll results (Wichmann 2010). Therefore, even if a pollster would include all WAPOR items in their survey report, we would expect that news reports would only include a couple. As there are fewer WAPOR items that can sensibly be included in a report on aggregate polls, we limit our test of this hypothesis to regular, non-aggregated polls. Still, we do expect a positive relationship between the number of WAPOR items in a survey report and news reports on that poll:

Hypothesis 1 The higher the number of WAPOR items included in a pollster survey report, the higher the number of WAPOR items included in media reports on this survey.

When it comes to the inclusion of the margin of error in news reports on polls, space constraints can be argued to be less of an issue. Here, the inclusion of the margin of error in a survey report can be a necessary but not a sufficient condition 
for including the margin of error in a news report on that poll. It seems unlikely for journalists to actively find out what the margin of error is if it is not included in the pollster's survey report. Especially because interpreting statistics can be hard for those without statistical training. Ranney et al. (2008) describe that 'statistics offered by media outlets are often rare, decontextualized, or disconnected' (p. 246). They even state that journalists are sometimes 'number-phobic.' Also, Maier (2003) showed that there is a high math anxiety among journalists. It is, thus, comfortable and easy for journalists to 'copy and paste' the margin of error from the pollster report. On the other hand, including the margin of error in a pollster report does not necessarily lead to its inclusion in the news report. Journalists might be unaware of its relevance, do not care about it, or simply ignore a margin of error. After all, correct usage of the margin of error usually means that differences and changes in the polls are often not statistically significant and, thus, should not be reported-or at least with a caveat. Journalists looking for 'news' might, therefore, regard the margin of error as a nuisance. Still, we would expect that, on average, journalists will rely on pollsters for the correct interpretation of the polls and if the margin of error is included in the survey report, it is expected to be more likely that it will feature in the news report as well:

Hypothesis 2 When pollsters report the margin of error this will increase the likelihood that news reports will include the margin of error.

Simply including the margin of error in a survey report might, however, not be sufficient, particularly if the margin of error is included (only) in a disclaimer rather than in the main body of the survey report. If the margin of error is more visible in the survey report, this would potentially increase the likelihood of its inclusion in the news report. Here, the increasing popularity of aggregate polls is relevant. One salient characteristic of many aggregate polls is the explicit presentation of the uncertainty of the estimates provided. These types of aggregates, based on Bayesian smoothing of available polling data using a Kalman filter (Jackman 2005), produce posterior distributions from which uncertainty estimates are easily derived. In the case of the Dutch aggregator Peilingwijzer, seat estimates for each party, are consistently presented as a $95 \%$ credible interval, for example '11-15 seats,' instead of a point estimate. While the point estimate can be found on the Peilingwijzer's website, it is not included in the headline figures. This potentially helps emphasize the uncertainty associated with opinion polling in news media reporting, because journalists are likely to rely on pollsters/aggregators for the correct presentation of their methods and findings:

Hypothesis 3 When pollsters report an uncertainty interval instead of a point estimate in their headline figures, the higher the likelihood that news reports will include the margin of error.

Even if news media refer to the margin of error in their news reports on polls, they might incorrectly interpret the poll's findings. They sometimes present the increase 
or decrease in a party's vote intention figures as statistically significant when it is not. The differences between party standings in one poll are also often incorrectly presented as statistically significant. The correct interpretation of these diachronic and synchronic differences in a poll is likely to depend on the inclusion of the margin of error. If pollsters do not include a margin of error, it is impossible to judge whether their findings can be generalized to the population. If they do present the margin of error, news media can be expected to be somewhat more cautious in drawing inferences from small differences and small changes in vote intention polls ${ }^{2}$ :

Hypothesis 4 When pollsters report the margin of error, this will increase the likelihood that news articles will correctly report the significance (or non-significance) of changes and differences in party support.

An alternative explanatory factor for the quality of poll coverage is the type of media in which the results are reported. With regard to newspapers, there is a difference between broadsheet and tabloid. In general, tabloids have stronger incentives to use sensationalism and simplification (Oleskog Tryggvason \& Strömbäck 2017, p. 6). Previous research found that the inclusion of methodological information is higher in the 'prestige press' (Brettschneider 2008). We therefore hypothesize:

Hypothesis 5 Tabloid media show lower levels of opinion poll coverage quality than broadsheet media.

\section{Data and methods}

We conducted a quantitative content analysis of voting intention poll reporting to test our hypotheses. We selected tabloid newspapers De Telegraaf, Algemeen Dagblad, Sp!ts and Metro, and broadsheet newspapers De Volkskrant, NRC NEXT, NRC Handelsblad, Financieel Dagblad, Trouw, Het Parool, Nederlands Dagblad, and Reformatorisch Dagblad. ${ }^{3}$ We included all national newspapers. ${ }^{4}$ Besides

\footnotetext{
2 One might remark that the margin of error presented by pollsters is often only a single figure independent of the party's actual size and based on the assumption that the margin of error is comparable to a random sample with a size equal to the poll, while in reality, all polls are based on not (fully) randomly selected internet panels. Moreover, the margin of error for a difference between two parties in a single poll or the difference between a party's score in two subsequent polls is not equal to the margin of error for a party's score in one poll. Still, the presentation of a margin of error is likely to signal that small differences and changes in polls are unlikely to be statistically significant and therefore inferences based on these findings are problematic.

3 Bos et al. classify De Volkskrant, NRC Handelsblad, and Trouw as broadsheet and classify De Telegraaf and Algemeen Dablad as tabloid. Metro and Sp!ts are mentioned as free newspapers but are treated as broadsheet media in their analysis (2010, p. 148). Broersma and Graham also classified De Volkskrant and NRC Handelsblad as broadsheet and Algemeen Dagblad and De Telegraaf as tabloid (2012, p. 409).

4 The total market share of these newspapers was in $201061.2 \%$, in $201264.5 \%$, and in $201760.2 \%$ (Mediamonitor 2018).
} 
newspapers, we also selected two of the main Dutch news websites that are related to the two main television news programs: NOS and RTL Nieuws. We selected all articles five weeks prior to the elections of $2010(n=231), 2012(n=456)$, and 2017 $(n=377)$ that mentioned polls and a polling institute. ${ }^{5}$

We used two coding units: $\operatorname{articles}^{6}(n=1066)$ and a mention of a party in a poll $(n=4493)$. Article-level variables were the publication date, source, the number of polls that were mentioned in the article, length of an article, and the type of reference to a poll. We distinguished five types of poll references: (1) general mention of 'the polls,' (2) mention of a poll result in passing, (3) poll result on party support is the main topic of the article, (4) poll result on another question is main topic of the article, and (5) other references, such as reference to local or foreign polls. With regard to the second type, mention of the poll in passing, we distinguished between an explicit mention of a number (the SP is now on 14 seats in poll X) and an implicit mention (such as PvdA is close behind the VVD in poll X). The 392 articles in categories 2 and 3 were used in the analyses. As some articles discuss polls from various companies, we arrive at a total of 524 cases of an article mentioning a poll from a particular company. ${ }^{7}$

Our second coding unit is the mention of a party in a poll. We opted for this coding unit instead of the poll, because multiple parties can be mentioned in a poll and the quality of reporting might vary per party. For one party, the change in support might be reported and interpreted correctly but not for another party. Of course, some information in a news report will pertain to all parties in the poll, such as the sample size. We coded the following variables for each party poll result mentioned in the news report: the party name, the number of seats reported, whether the reported figures were correct, the WAPOR items included in the article, whether the margin of error was mentioned, and if the results were correctly interpreted. All coding was done by one of the authors (the coding scheme and details of an inter-coder reliability check can be found in the Online Supplemental Materials B-D).

Our independent variable, the quality of the survey report prepared by the pollsters, was measured by analyzing these reports in the same manner as the news articles. We retrieved pollsters' reports from their website or, if the poll was no longer

\footnotetext{
5 Search terms: (peiling OR peilingen OR peilingwijzer) AND ("maurice de hond" OR ipsos OR synovate OR eenvandaag OR peil.nl OR peilingwijzer OR nipo OR kantar OR "I\&O" OR LISS). The news articles of RTL Nieuws were selected by searching for the word 'peiling,' since the search engine did not allow multiple search terms. For the NOS, the search strategy was also a bit deviant. In 2010, we manually selected all articles about politics. After retrieving the original webpage by using webarchive.org, we searched for the word 'peiling.' For the articles of NOS in 2012 and 2017, we used the original search terms with Google Search. When a webpage was no longer available, we used webarchive.org. Despite our thorough attempts to get a complete sample, we admit that it is possible that some articles or webpages are missing because they were no longer available.

${ }^{6}$ In some cases, one article reported on polls from multiple companies. As the independent variables on the survey report could take on different values, we treat these as separate observations for the purpose of testing Hypotheses 1 to 3.

${ }^{7}$ For the analysis in which the number of WAPOR items and the reporting of the margin of error was the dependent variable, we only included type- 2 articles (mention of a poll in passing), in which the number of seats/percentage was explicitly reported.
} 
available from the pollster's website, via webarchive.org. In a few cases, we could not locate the original reports of the poll. However, as pollsters tend to stick to a particular template of poll reporting, at least during the same election campaign, in these cases, we assumed that the reports included equivalent information to the reports in the same campaign that we could retrieve. ${ }^{8}$

The major Dutch polls that we have included all use online panels, except for the Peilingwijzer which is a polling aggregator. The LISS panel is a probability sample based on a simple random sample of addresses from the Dutch population register (LISS panel, n.d.), while the other panels use diverse recruitment strategies (Van Ossenbruggen et al. 2006). Peil.nl is a completely opt-in panel (De Hond, n.d.). GfK, Kantar (TNS NIPO), and Ipsos partially used opt-in recruitment in the past (Van Ossenbruggen et al. 2006) but most have phased this out in recent years.

The inclusion of methodological information is our first measure of quality (Vögele and Bachl 2018; Welch 2002; Andersen 2000; Hardmeier 1999). The most important methodological criteria, ${ }^{9}$ based on the extensive list of WAPOR and AAPOR, are (1) sample size, (2) field dates, (3) sampling method, (4) data collection, (5) weighting procedure, and (6) the population. Just as Vögele and Bachl (2018), we counted how many criteria were included and created an index score ranging from 1 till 6 .

Our second quality measure is whether the margin of error is mentioned in the article. If a general remark about the margin of error was made, even in a disclaimer below the article, we coded this as included for all parties in that poll. The same applied to pollsters' survey reports. Since mentioning the margin of error is not a guarantee for the correct interpretation of poll results, our third quality measure is about the correct interpretation of the margin of error. We make a distinction between synchronous and diachronic comparisons. Synchronous horse-race statements indicate that a party leads or trails. Diachronic horse-race statements are about whether the support for a given party is rising, declining or stable across two successive polls (Pétry and Bastien 2013). To test whether the authors correctly interpreted the poll results, we coded if the changes or differences they described were statistically significant. If they were not significant, we also coded whether the author mentions the insignificance. We tested the significance of the changes and differences, based on the original (aggregate) poll results and the sample size (see Franklin 2007). ${ }^{10}$ For this calculation, we assumed that the error associated with the poll was comparable to the error associated with a random sample, which is similar to the margin of errors commonly reported by the pollsters themselves.

We include two control variables in the models: the log of the length of the article in words and the type of article. The latter variable distinguishes between articles in

\footnotetext{
${ }^{8}$ For Kantar, we could find only two reports from 2010. We used these reports as an indication of the other reports from that year, since these reports tend to have the same format for every report. We followed the same logic for the reports of the LISS panel in 2017.

${ }_{9}$ We excluded mentioning the polling company, since we selected newspaper articles based on mentioning polling institutes.

${ }^{10}$ For the aggregate poll, we used the significance of differences and changes as reported on the website of the Peilingwijzer.
} 
Table 2 Percentage of news reports (about polls) and survey reports that contain information on specific methodological aspect

\begin{tabular}{|c|c|c|c|c|c|c|}
\hline & \multicolumn{3}{|c|}{ News reports } & \multicolumn{3}{|c|}{ Survey reports } \\
\hline & 2010 & 2012 & 2017 & 2010 & 2012 & 2017 \\
\hline Universe & 0.0 & 2.4 & 2.7 & 14.3 & 22.0 & 25.9 \\
\hline Sampling method & 2.9 & 2.4 & 2.7 & 0.0 & 39.0 & 25.9 \\
\hline Non-response rate & 0.0 & 1.6 & 0.0 & 0.0 & 12.2 & 24.1 \\
\hline Sample size & 14.7 & 14.5 & 0.0 & 23.8 & 36.6 & 41.4 \\
\hline Weights & 0.0 & 0.0 & 0.0 & 23.8 & 26.8 & 25.9 \\
\hline Fieldwork dates & 0.0 & 4.8 & 2.7 & 23.8 & 36.6 & 36.2 \\
\hline Data collection method & 8.8 & 21.8 & 45.9 & 23.8 & 26.8 & 32.8 \\
\hline Margin of error & 5.9 & 28.2 & 64.9 & 9.5 & 39.0 & 67.2 \\
\hline$N$ (articles) & 34 & 124 & 37 & & & \\
\hline
\end{tabular}

Figures relate only to news reports that focused solely or mainly on a specific vote intention poll. In case, multiple polls are discussed in a single article, any mention of the item counts. Table A1 in the Online Supplemental Materials excludes the articles that use the Peilingwijzer

which the poll is the main topic of the article (type 3 above) and articles in which a poll is mentioned in passing: 'in-line poll reference' (type 2 above).

Our modeling strategy recognizes the hierarchical and longitudinal nature of our data. We have observations from various different polling companies, from different election campaigns (years), which are published in various news outlets. Our observations regarding the correct presentation of polls in terms of changes over time or differences between parties are in some cases clustered in a news article, i.e., when one news article reported changes or differences involving more than one party. We ran multilevel regression models (a linear model for the WAPOR index and binary logistical models for the other dependent variables). Because we only have three years in the data, we added years as fixed effects. Our models on the WAPOR index and margin of error include random intercepts for poll company, whereas our models of the correct interpretation of change/differences include random intercepts for article (see Online Supplemental Materials E for the full model specification). All models are estimated using the lme4 package in R (Bates et al. 2015). ${ }^{11}$

\section{Results}

The quality of opinion poll reporting in the Netherlands is very low (see Table 2). Very few news reports on polls contain information on the universe polled, the sampling method, non-response rate, sample size, weights, or fieldwork dates. The data

\footnotetext{
11 We have also estimated version of the models with clustered standard errors by polling company or by article, instead of using random intercepts for these variables. This yields similar results to the ones presented.
} 
collection method and margin of error are mentioned quite frequently, especially in the election of 2017. As we will see, for a part, this can be attributed to news reports on the aggregate poll Peilingwijzer, but in general, news reports include the margin of error more frequently in 2012 (28.2\%) and 2017 (64.9\%) than in 2010 (5.9\%).

The survey reports prepared by pollsters include much more information about the polls, especially in recent years. Note that we analyzed the reports or press releases of the polling companies, not whether some of this information might have been available elsewhere on their website. The margin of error was mentioned in almost $70 \%$ of the survey reports in 2017, which is a clear increase from the 2010 figure (about 10\%). The figures for 2017 are dragged down somewhat by the presence of an aggregate poll in our dataset, for which arguably not all of these items apply. All in all, the figures are higher than for media reports and have increased in the last few years. Some pollsters, most notably I\&O Research, Kantar (formerly TNS NIPO) and EenVandaag/GfK included (almost) all of the items mentioned in Table 2 in their survey reports in 2017.

Table 3 provides insight into the explanation of the quality of media reports on vote intention polls in the Netherlands. In the first model, the dependent variable is the number of WAPOR items that are mentioned in the news report. The main independent variable, the number of WAPOR items included in the pollster's survey report, is not significantly associated with the number of items in the news report. As we saw in the descriptive statistics, mentions of these methodological aspects are quite rare. We see that longer articles tend to mention more items, and that articles that provide merely an in-line reference to polls ('Party $\mathrm{X}$ was on $7 \%$ in this week's Ipsos poll') understandably include fewer WAPOR items than news articles that focused entirely on opinion poll results. We excluded the aggregated poll from the analysis in model 1, because not all of the WAPOR items apply to such a poll, so this does not drive the lack of an effect of inclusion of WAPOR items in the survey report. Our empirical analysis does not provide support for Hypothesis 1 (see Online Supplemental Materials F for a separate analysis of two WAPOR items that are regularly included in news reports).

Mentioning the margin of error is not included in the list of WAPOR items in our analysis, but it can be argued to be especially important when making inferences from the poll to the general population of voters. While we do find a positive effect of the margin of error being included in the pollster's survey report, this just fails to achieve conventional levels of statistical significance. In model 3 , we distinguish between two ways in which the margin of error can be reported by pollsters. The first is the traditional margin of error, usually phrased something like 'the margin of error for this poll is $\pm 2.5 \%$.' It is not uncommon for these statements to be included (in small print) towards the bottom of the survey report. A second way in which the uncertainty of a polling result can be reported is by providing an uncertainty interval for each party, i.e., 'Party $\mathrm{X}$ is on 11 to 15 seats.' This is the way in which the aggregate poll Peilingwijzer presents its estimate. In fact, when it comes to the seat estimates for each party, which are traditionally reported in Dutch media instead of percentages, the Peilingwijzer only provides the uncertainty interval for each party. The point estimate is available 
Table 3 Regression models of news report quality

(1) WAPOR index (2) Margin of error (3) Margin of error

\begin{tabular}{ll}
\hline (Intercept) & -0.26 \\
& $(0.23)$ \\
Pollster WAPOR index & -0.0 \\
& $(0.03)$
\end{tabular}

Margin of error in survey report

$-5.45^{* * *} \quad-5.94 * * *$

Type of MOE in survey report (Ref.:

None)

Traditional MOE

Uncertainty interval

Control variables

Article length $(\log )$

$\begin{array}{lll}0.06 & 0.06 & 0.05 \\ (0.03) & (0.15) & (0.15) \\ 0.27^{* * *} & 1.62^{* * *} & 1.75^{* * *} \\ (0.07) & (0.38) & (0.40) \\ -0.00 & 2.53^{*} & 2.52^{*} \\ (0.08) & (1.02) & (1.03) \\ -0.08 & 2.10 & 2.18^{*} \\ (0.13) & (1.13) & (1.11) \\ 775.61 & 411.87 & 395.22 \\ 807.68 & 441.64 & 429.25 \\ -379.81 & -198.93 & -189.61 \\ 407 & 520 & 520 \\ 6 & 7 & 7 \\ 0.01 & 1.35 & 0.00 \\ 0.36 & & \end{array}$

Full article (Ref.: In-line reference)

Year $=2012$

$-0.00$

$2.53 *$

$2.52 *$

Year $=2017$

$-0.08$

\section{$(1.03)$}

AIC

(0.13)

BIC

Log Likelihood

Num. obs

Num. groups: Poll_company

Var: Poll_company (Intercept)

Var: Residual

2.10

429.25

$-189.61$

$* * * p<0.001 ; * * p<0.01 ; * p<0.05$. The dependent variable concerns the quality of the news report. Model 1 is a linear regression with random effects for pollster. Models 2 and 3 are binary logistic models with random effects for pollster

from the website but is substantially less visible than the uncertainty interval. Therefore, we hypothesized that especially such an uncertainty interval in the survey report would increase the chances of an uncertainty estimate being presented in a news report. Our empirical analysis provides support for this hypothesis. The coefficient for this variable is statistically significant and large. The predicted probability of inclusion of a margin of error in a news report on the poll is $74 \%$ compared to $7 \%$ for a 'traditional' margin of error and $6 \%$ when no margin of error estimate was presented in the survey report. This supports the argument that by making the uncertainty interval, the default presentation of the poll results, 
Table 4 Regression models of correct interpretation of differences and changes in polls

\begin{tabular}{lll}
\hline & $\begin{array}{l}(1) \text { Difference between } \\
\text { parties }\end{array}$ & $(2)$ Change over time \\
\hline (Intercept) & -3.11 & $-5.85^{* * * *}$ \\
& $(6.12)$ & $(1.52)$ \\
Type of MOE in survey report (Ref.: None) & & \\
Traditional MOE & 0.05 & $-0.89^{*}$ \\
& $(0.90)$ & $(0.42)$ \\
Uncertainty interval & $17.94^{* * *}$ & 1.12 \\
& $(2.61)$ & $(0.61)$ \\
Control variables & & \\
Article length (log) & -0.65 & $0.44 *$ \\
& $(0.93)$ & $(0.22)$ \\
In-line poll reference (Ref.: full article) & -1.42 & 0.14 \\
& $(1.69)$ & $(0.46)$ \\
Year=2012 & -0.16 & $2.22 * * *$ \\
& $(1.67)$ & $(0.55)$ \\
Year=2017 & -0.23 & $3.91 * * *$ \\
& $(2.42)$ & $(0.76)$ \\
AIC & 395.69 & 778.08 \\
BIC & 428.37 & 815.22 \\
Log Likelihood & -189.85 & -381.04 \\
Num. obs & 439 & 767 \\
Num. groups: Article_ID & 162 & 241 \\
Var: Article_ID (Intercept) & 243.40 & 3.45 \\
\hline
\end{tabular}

${ }^{* * *} p<0.001 ; * * p<0.01 ; * p<0.05$. The dependent variable concerns the quality of the news report. Binary logistic regression models with random effects for article

one can significantly increase the chances that this information is presented in news reports.

\section{Interpreting poll findings substantively}

Presenting the margin of error of a poll is one thing, correctly interpreting the findings of the poll is another. We analyze both synchronic comparisons, claims on the differences between two parties in a poll ('Party A is bigger than party B') and diachronic comparisons, the change in party vote intention between two or more polls ('Party A's support has increased'). We hypothesized that these types of comparisons are more likely to be reported correctly, i.e., only claimed if they are statistically significant, when the pollster provides a margin of error. In our analysis, we again distinguish between a traditional margin of error and the presentation of uncertainty intervals.

Just under half (43\%) of the synchronic comparisons made in the news reports we analyzed were incorrect when we take the margin of error of the poll into account. 
We observed a strong association between the report of uncertainty intervals by the pollster and the correct interpretation of differences between parties in news reports (see Model 1 in Table 4). We find no difference in this respect between pollster survey reports that report a regular margin of error or none at all. Again, it seems that presenting party seat estimates as ranges signal the uncertainty associated with these estimates. If two seat ranges overlap, journalists might be less likely to claim that one party is larger than the other. ${ }^{12}$

We do, however, not observe this difference for diachronic comparisons (see Model 2 in Table 4). Most claims about a party's increase in support between two (or more) polls were incorrect when taking into account a poll's margin of error $(65 \%)$. We observe no substantial differences here depending on whether the pollster reported a margin of error, an uncertainty interval or no uncertainty estimate at all. If anything, news reports on a poll for which the survey report included a 'regular' margin of error, score slightly lower than when no margin of error was included in the survey report. This is perhaps somewhat surprising, given the relatively strong effects in the previous models. When analyzing the newspaper reports, we did often see that journalists made claims like 'Party A is on 20-24 seats in the newest poll. That is one seat more than the previous poll, when it was on 19-23 seats.' So, whereas it seems that the use of uncertainty intervals did affect the reporting on differences between parties, journalists seem to still report changes from one poll to another, even if those are not statistically significant. ${ }^{13}$

\section{Differences between media types}

At last, we hypothesized that the type of media could be an alternative explanatory factor for the quality of poll coverage. We expected that broadsheet media are better at reporting about polls than tabloid media. In our analysis, we replicated the previous models, adding a variable media type that distinguishes between tabloid newspapers, broadsheet newspapers, and TV news websites (see Table 5). Our evidence is somewhat mixed. We do not find a significant difference between broadsheet newspapers for any of the quality indicators. We do find that TV news websites score higher, on average, than tabloid newspapers when it comes to the number of WAPOR items mentioned and the probability of including the margin of error. We find no media effects, however, for the correct reporting of changes over time and between parties. Overall, TV news websites seem to be more likely than both tabloid and broadsheet newspapers to include methodological information about opinion polls, even when controlling for other factors, such as article length, and the

\footnotetext{
12 We note that this is actually too conservative a criterion. A margin of error for the difference between two parties should in fact be calculated. As the variance of the difference between two parties is equal to the sum of their variances minus two times their covariance, an uncertainty interval or confidence interval for the difference between two parties will be smaller than simply adding up the margin of error for the two point estimates.

13 When a news report noted a change but explicitly stated that this was not statistically significant, we coded this as a correct interpretation.
} 


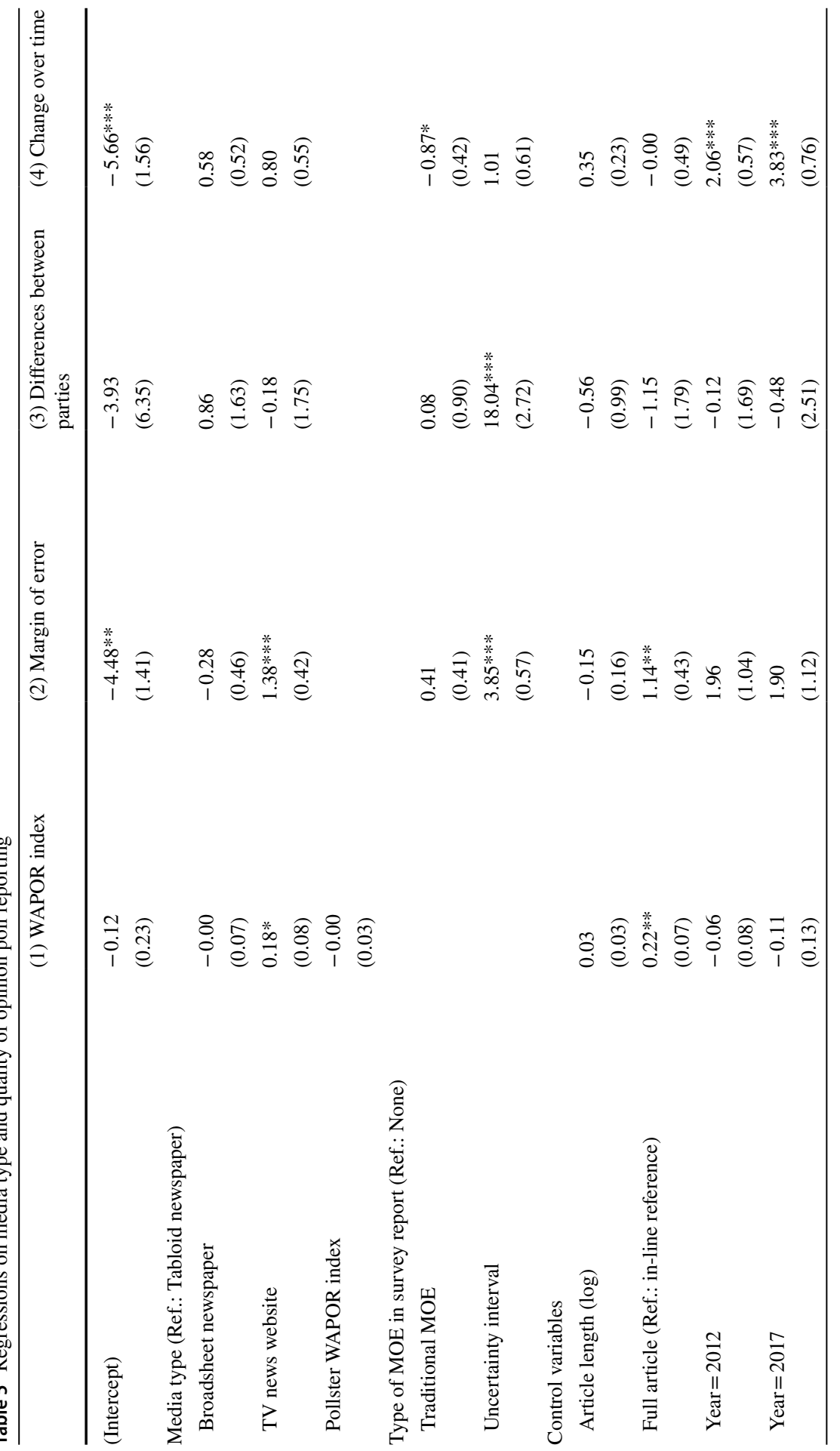

s.tic 


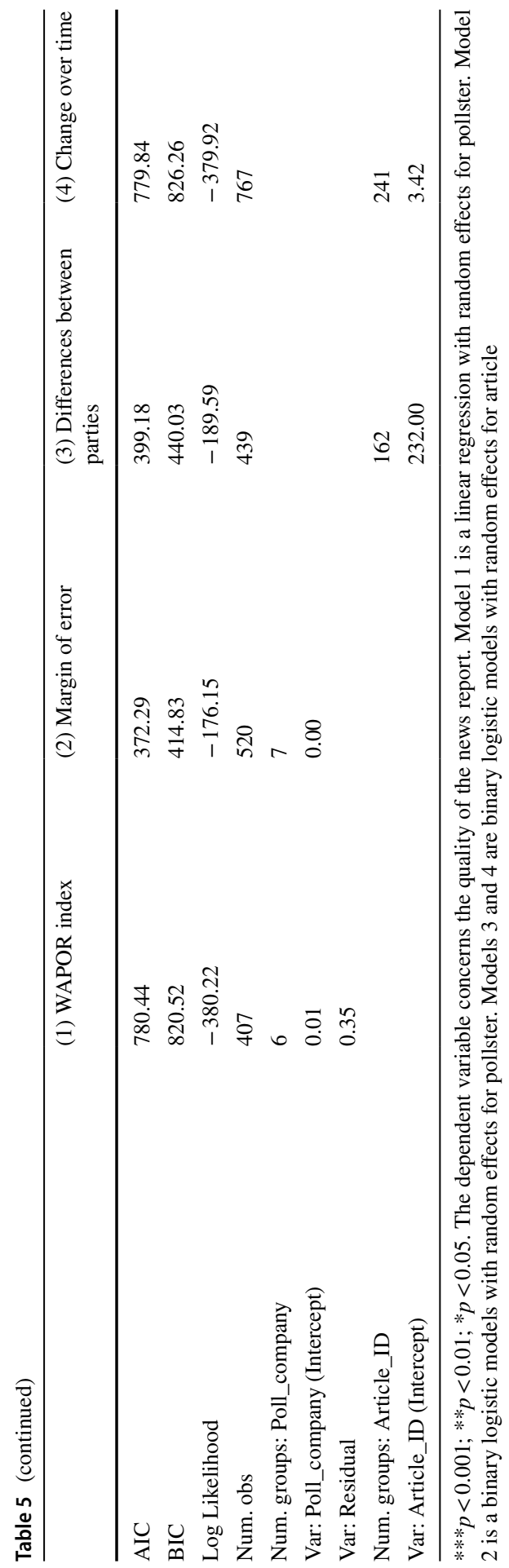


question whether the margin of error was included in the pollster report. Particularly tabloid media score poorly in this regard, which is in line with previous research (Oleskog Tryggvason and Strömbäck 2017).

\section{Conclusion and discussion}

The quality of poll reporting in the Netherlands is low, also in comparison to other countries. Our main focus was the difference that survey reports by pollsters might make in terms of the quality of media reporting of vote intention polls. Our results suggest that reporting the margin of error in a survey report can improve the quality of news reporting about polls, particularly when including the margin of error as an 'uncertainty interval.' Media reports about a poll that did this were more likely to mention the margin of error and to correctly interpret the significance of differences between parties in a poll. We suggest that this is related to the fact that reporting an uncertainty interval makes it easy for journalists to report the margin of error and difficult not to do so, since the point estimate is less clear from the headline figures. Moreover, the ranges make it easier to report on (in)significant differences between parties in that same poll: when seat ranges of two parties overlap, this clearly suggests that no significant difference between two parties exists. Since previous research indicates that type of media can also affect the quality of poll reporting, we included these two factors in our analysis. For media type, we found diverse effects that mainly suggested that the websites of the TV news programs score better in this respect than both tabloid and broadsheet newspapers.

While our finding of a positive relationship between reporting the uncertainty interval in survey reports and news reports is certainly hopeful from a societal perspective, our study can only offer a tentative interpretation of how this relationship comes about. The relationship we found between pollsters' reports and news media reports on polls might be wholly or partly due to a selection effect: media that are particularly attentive to good poll reporting could choose to report only polls from pollsters that report uncertainty intervals. In that case, the inclusion in the report of the uncertainty interval is not the causal factor at play, but the relationship observed is driven by the question whether a news medium understands and is attentive to polling methodology. One consequence could be that pollsters should not only present polling methodology information in their report, but also engage with news media to inform them about the value of such information.

One important issue that we have not analyzed in detail is the question of how prominently the survey report mentioned the margin of error. In our data, the poll aggregator that reported the uncertainty interval did so very prominently, in the 'headline figures.' Whether including an uncertainty interval less prominently, for example, in a separate table in the report with point estimates still taking center stage, has the same effects remains to be seen. Further analysis might also focus on the substantive interpretations that pollsters provide for their data and the likelihood of these being copied in news reporting. For example, if a pollster claims that a party has gained support, one might expect journalists to trust this information, whether correct or not. 
Our results show that merely the availability of a poll of polls does not necessarily improve the quality of newspaper reporting; it is the way in which the data are presented by pollsters (and poll aggregators) and the way in which the publication is organized that matter most. By presenting uncertainty intervals in the form of seat ranges rather than point estimates, for example, it is easier to communicate the uncertainty associated with opinion polls. Working together with journalists can also help to avoid making factual errors in interpreting opinion poll data, but this of course requires a willingness to do so on the part of both journalists and pollsters.

Supplementary Information The online version contains supplementary material available at https://oi. org/10.1057/s41269-021-00208-5.

Acknowledgements An earlier version of this paper was presented at the Annual Conference of the Dutch and Flemish Political Science Organisations (Politicologenetmaal), 13-14 June 2019 and the panel Political Communication in Times of Elections, ECPR General Conference, 4-7 September, 2019. We thank the participants and in particular the discussants, Martin Rosema and Marco Mazzoni, for their comments and suggestions.

\section{Declarations}

Conflict of interest Tom Louwerse developed and maintains the Peilingwijzer, an aggregate of Dutch opinion polls. This is a non-commercial academic project.

\section{References}

Aalberg, T., J. Strömbäck, and C.H. de Vreese. 2011. The framing of politics as strategy and game: A review of concepts, operationalizations and key findings. Journalism 13 (2): 162-178.

Andersen, R. 2000. Reporting public opinion polls: The media and the 1997 Canadian election. International Journal of Public Opinion Research 12 (3): 285-298.

Bates, D., M. Maechler, B. Bolker, and S. Walker. 2015. Fitting linear mixed-effects models using lme4. Journal of Statistical Software 67 (1): 1-48. https://doi.org/10.18637/jss.v067.i01.

Bhatti, Y., and R.T. Pedersen. 2016. News reporting of opinion polls: Journalism and Statisical Noise. International Journal of Public Opinion Research 28 (1): 129-141.

Bos, L., W. van der Brug, and C. de Vreese. 2010. Media coverage of right-wing populist leaders. Communications 35 (2): 141-163.

Brettschneider, F. 1997. The press and the polls in Germany, 1980-1994 poll coverage as an essential part of election campaign reporting. International Journal of Public Opinion Research 9 (3): 248-265.

Brettschneider, F. 2008. The news media's use of opinion polls. In The SAGE handbook of public opinion research, ed. W. Donsbach and M.W. Traugott. London: Sage.

Broersma, M., and T. Graham. 2012. Social media as beat. Journalism Practice 6 (3): 403-419.

Chang, T. 1999. Reporting public opinion in Singapore. Journalistic practices and policy implications. The International Journal of Press Politics 4 (1): 11-28.

de Hond, M., de (n.d.). Onderzoeksopzet. Retrieved on April 7, 2021 from https://home.noties.nl/peil/ onderzoeksopzet/.

De Vreese, C., and H.A. Semetko. 2002. Public perception of polls and support for restrictions on the publication of polls: Denmark's 2000 Euro Referendum. International Journal of Public Opinion Research 14 (4): 367-390.

Ferguson, P.A., and C. de Clercy. 2005. Regulatory compliance in opinion poll reporting during the 2004 Canadian election. Canadian Public Policy/analyse De Politiques 31 (3): 243-257.

Franklin, C.H. 2007. The "Margin of Error" for Differences in Polls. Retrieved on May 30, 2021 from https://abcnews.go.com/images/PollingUnit/MOEFranklin.pdf.

Frankovic, K.A. 2004. Reporting "The Polls" in 2004. The Public Opinion Quarterly 69 (5): 682-697. 
Hardmeier, S. 1999. Political poll reporting in Swiss print media: Analysis and suggestions for quality improvement. International Journal of Public Opinion Research 11 (3): 257-274.

Hardmeier, S. 2012. The effects of published polls on citizens. In The SAGE handbook of public opinion research, ed. W. Donsbach and M.W. Traugott, 504-514. London: Sage.

Hardmeier, S., \& Roth, H. 2001. Towards a systematic assessment of impact of polls on voters: A metaanalytical overview. Paper presented at the 54th annual conference of the World Association for Public Opinion Research, Rome.

Holtz-Bacha, C. 2012. Opinion polls and the media in Germany: A productive but critical relationship. In Opinion polls and the media reflecting and shaping public opinion, ed. C. Holtz-Bacha and J. Strömbäck. Basingstoke: Palgrave Macmillan.

Iyengar, S., J. Norpoth, and K.S. Hahn. 2004. Demand for election news: The horserace sells. The Journal of Politics 66 (1): 157-175.

Jackman, S. 2005. Pooling the polls over an election campaign. Australian Journal of Political Science 40 (4): 499-517.

Koetsenruijter, A.W.M. 2011. Using numbers in news increases story credibility. Newspaper Research Journal 32 (2): 74-82.

Larsen, E.G., and Z. Fazekas. 2019. Transforming stability into change: How the Media select and report opinion polls. The International Journal of Press/Politics. 7 (1): 23-35.

Larson, S.G. 2003. Misunderstanding margin of error network news coverage of polls during the 2000 general election. Press/Politics 8 (1): 66-80.

Leijenaar, M., and K. Niemöller. 1987. Tussen peilglas en glazen bol: Opiniepeilingen en de Tweede Kamerverkiezingen 1986. In De strijd om de meerderheid: De verkiezingen van 1986, ed. C. van der Eijk and P. Van Praag, 29-47. Amsterdam: CT Press.

LISS panel (n.d.) About the panel. Retrieved on April 7, 2021 from https://www.lissdata.nl/about-panel.

Maier, S.R. 2003. Numeracy in the newsroom: A case study of mathematical competence and confidence. Journalism and Mass Communication Quarterly 80 (4): 921-936.

Matthews, J.S., M. Pickup, and F. Cutler. 2012. The mediated horserace: Campaign polls and poll reporting. Canadian Journal of Political Science 45 (2): 261-287.

Mediamonitor. 2018. Bereik, oplage en marktaandelen Nederlandse dagbladenmarkt 2017. Retrieved on April 6, 2021 from https://www.mediamonitor.nl/nieuws/bereik-oplage-en-marktaandelen-neder landse-dagbladenmarkt-2017/.

Morton, R.B., D. Muller, L. Page, and B. Torgler. 2015. Exit polls, turnout, and bandwagon voting: Evidence from a natural experiment. European Economic Review 77: 65-81.

Moy, P., and E.M. Rinke. 2012. Attitudinal and behavioral consequences of published opinion polls. In Opinion polls and the media reflecting and shaping public opinion, ed. C. Holtz-Bacha and J. Strömbäck, 225-245. New York: Palgrave Macmillan.

Mudde, T. 2012. Aan de leiband van De Hond Kiezerspeilingen. De Volkskrant. p. 2.

NRC Handelsblad. 2012. Dolgedraaid door de peilingen. NRC Handelsblad.

Oleskog Tryggvason, P.O., and J. Strömbäck. 2017. Fact or fiction? Journalism Studies 19 (14): 2148-2167.

Ossenbruggen, R., van, Vonk, T., and Willems, P. 2006. Results Dutch Online Panel Comparison Study (NOVPO). Retrieved on April 7, 2021 from http://www.websm.org/uploadi/editor/1411028786 Results_NOPVO_English.pdf

Patterson, T.E. 2005. Of polls, mountains: U.S. journalists and their use of election surveys. The Public Opinion Quarterly 69 (5): 716-724.

Petersen, T. 2012. Regulation of opinion polls: A comparative perspective. In Opinion polls and the media reflecting and shaping public opinion, ed. C. Holtz-Bacha and J. Strömbäck, 47-68. New York: Palgrave Macmillan.

Pétry, F., and F. Bastien. 2013. Follow the pollsters: Inaccuracies in media coverage of the horse-race during the 2008 Canadian election. Canadian Journal of Political Science 46 (1): 1-26.

Portilla, I. 2016. The inclusion of methodological information in poll-based news: How do Spanish newspapers conform to professional recommendations and legal requirements? Journalism 17 (1): 35-48.

Ranney, M., Rinne, L., Yarnall, L., Munnich, E., Miratrix, L., and Schank, P. 2008. Designing and assessing numeracy training for journalists: Toward improving quantitative reasoning among media consumers. Computer-Supported Collaborative Learning Conference CSCL. 246-253.

Rosenstiel, T. 2005. Political polling and the new media culture: A case of more being less. Public Opinion Quarterly 69 (5): 698-715. 
Sonck, N., and G. Loosveldt. 2008. Research note: Making news based on public opinion polls The Flemish case. European Journal of Communication 23 (4): 490-500.

Stolwijk, S.B. 2017. Who is driving whom: The media, voters and the bandwagon (Doctoral dissertation).

Stolwijk, S.B., and A.R. Schuck. 2019. More interest in interest: Does poll coverage help or hurt efforts to make more young voters show up at the ballot box? European Union Politics 20 (3): 341-360.

Strömbäck, J. 2009. Vox Populi or vox Media? Opinion Polls and the Swedish Media, 1998-2006. Javnost - The Public 16 (3): 55-70.

Szwed, R. 2011. Printmedia poll reporting in Poland: Poll as news in Polish parliamentary campaigns, 1991-2007. Communist and Post-Communist Studies 44: 63-72.

Trouw. 2012. De dolgedraaide opiniepeilingen negeren, of niet? Trouw. p. 25.

van Holsteyn, J.J.M., and R.B. Andeweg. 1988. De pers in de peiling: Peilingen in de pers. In Tussen steekproef en stembus: Beschouwingen over verkiezingspeilingen naar aanleiding van de discrepantie tussen de peilingen en de verkiezingsuitslag van 21 mei 1986, ed. R.B. Andeweg, 81-100. Leiden: DSWO Press.

Vögele, C., and Bachl, M. 2018. The quality of public opinion poll coverage during German Federal Election Campaigns. https://doi.org/10.31219/osf.io/38yjh

WAPOR. 2018. Resources for Journalists. Retrieved on November 12, 2018 from https://wapor.org/resou rces/resources-for-journalists/.

Weaver, D., and S.T. Kim. 2002. Quality in public opinion poll reports: Issue salience, knowledge, and conformity to AAPOR/WAPOR standards. International Journal for Quality in Health Care 14 (2): 202-212.

Welch, R.L. 2002. Polls, polls, and more polls. Press/politics 7 (1): 102-114.

Wichmann, W. 2010. Too many technical details hinder recall of poll results. Newspaper Research Journal 31 (3): 36-49.

Wichmann, W., and F. Brettschneider. 2009. American and German elite journalists' attitudes toward election polls. International Journal of Public Opinion Research 21 (4): 506.

Publisher's Note Springer Nature remains neutral with regard to jurisdictional claims in published maps and institutional affiliations.

Tom Louwerse is an associate professor of Political Science at Leiden University.

Rozemarijn E. van Dijk is a Ph.D. student in Political Science at the University of Antwerp. 